\title{
Bruck Syndrome: A Rare Disorder in New-Born with Fractures and Contractures
}

\author{
Dhaubhadel S', Chapagain $\mathrm{RH}^{2}$, Baniya $\mathrm{B}^{1}$, Joshi H' ${ }^{1}$, Paudel KP
}

\begin{abstract}
Bruck syndrome is a very rare autosomal recessive syndrome consisting of bone fragility and congenital joint contractures. It is considered as a combination of arthrogryposis multiplex congenita and osteogenesis imperfecta, while some consider it as the autosomal recessive variant of osteogenesis imperfecta. According to the genotype, it has been classified into types 1 and 2. To our knowledge, only about 28 patients of this syndrome have been reported so far worldwide with none been reported from Nepal. Here, we present a patient with generalized osteopenia, bilateral femur fracture and congenital joint contractures of distal extremities.
\end{abstract}

Key words: Arthrogryposis; Osteogenesis imperfecta; Bruck syndrome; Neonate; FKBP10 gene

\section{Introduction}

B uck syndrome (BS) is an extremely rare congenital disorder with an incidence of less than $1 / 1000000$. This peculiar illness combines symptoms of osteogenesis imperfect (OI) and arthrogryposis multiplex congenita, presenting with bone fragility manifesting as multiple and recurrent fractures and congenital joint contractures. It has been considered as an autosomal recessive form of osteogenesis imperfecta $(\mathrm{OI})^{1}$ while some cases have found to have sporadic mutation. Alfred Bruck first described in 1878 the symptoms of congenital bone fragility and congenital contractures of the large joints ${ }^{2}$. Initially, the mutations discovered in BS patients were PLOD2 mutations, but recently evidence for the role of chromosome 17 has identified the FKBP10 gene as a responsible locus ${ }^{3,4,5}$.

BS has been classified into types 1 and 2 which are clinically indistinguishable ${ }^{6}$.

The characteristics of Bruck syndrome include bone fragility leading to multiple and recurrent fractures, congenital joint contractures with or without webbing (pterygia), scoliosis, and osteoporosis. They may or may not have blue sclera and usually don't present with dentinogenesis imperfecta and hearing loss.

We report a case of Bruck Syndrome, diagnosed clinically and radiologically in a new-born baby admitted in the NIMCU (Neonatal Intermediate Medical Care Unit) ward of Kanti Children's Hospital which, to our knowledge is the first case to be reported in Nepal so far.
${ }^{1}$ Dr. Suraj Dhaubhadel, MBBS. MD Resident, ${ }^{2}$ Dr. Bimala Baniya, MBBS. MD Resident, ${ }^{3} \mathrm{Dr}$. Hema Joshi, MBBS. MD Resident, ${ }^{4} \mathrm{Dr}$. Ram Hari Chapagain, MBBS. MD. Assistant Professor, ${ }^{5}$ Dr. Krishna Prasad Paudel, MBBS. MD. Associate Professor. All from the National Academy of Medical Sciences (NAMS), Kanti Children's Hospital.

\section{Address for correspondence \\ Dr. Suraj Dhaubhadel \\ E-mail: sooraz123@gmail.com}

\section{How to cite}

Dhaubhadel S, Chapagain RH, Baniya B, Joshi H, Paudel KP. Bruck Syndrome: A Rare Disorder in New-Born with Fractures and Contractures. J Nepal Paediatr Soc 2017;37(3):276-279.

doi: http://dx.doi.org/10.3126/jnps.v37i3.18103

This work is licensed under a Creative Commons Attribution 3.0 License. 


\section{The Case}

A 26 days old term but small for gestational age male neonate born from non-consanguineous marriage with birth weight of $1.8 \mathrm{~kg}$ and uneventful antenatal history without any exposure to drugs or radiation presented to Emergency Department of Kanti Children's Hospital with the complaint of fever for three days.

He also had history of bilateral fracture of shaft of femur and flexion deformity of distal parts of all four limbs (Figure 1). He is the third child of the family with no history of abortion, still-birth or sibling death or bone or connective tissue disorder in the same family. The child is still not immunized, and his elderly brother and sister healthy and doing well with their studies.

On examination, the baby weighed $2 \mathrm{~kg}$, spanned $41 \mathrm{~cm}$ with a head circumference of $32 \mathrm{~cm}$ which meant that all his growth parameters fell below-3 Z-score according to WHO growth charts

General examination showed the baby was lethargic with decreased activity and diminished reflexes and contractures in the distal parts of all four limbs. His lateral to antero-posterior chest diameter ratio of 1.25:1 and anterior fontanelle was at level measuring $1.8 \mathrm{~cm} \times 1 \mathrm{~cm}$ with normal vitals and perfusion. On head to toe examination, there was no visible facial dysmorphism, with normal sclera and eyes which was later confirmed by an ophthalmologist.

He had a slightly enlarged right ear which was thin and elastic but his hearing assessment couldn't be performed due to age factor and his teeth had still not erupted. Similarly, his urethral and anal opening were normal, but had right undescended testis and a longitudinal blind dimple measuring $1 \mathrm{~cm}$ and $0.8 \mathrm{~mm}$ proximal to anal opening.

On examination of joints and limbs, mild lateral scoliosis of thoracic spine was observed. There were

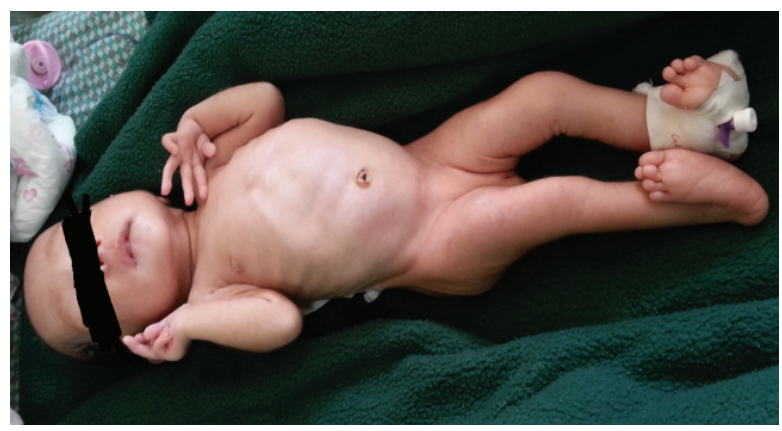

Fig 1: The new-born with the typical flexion deformities in distal parts of all four extremities. no syndactyly or polydactyly but flexion deformity in the distal parts of all four limbs were observed without pterygia which was more pronounced in both ankle joints (Figure 2) with convex soles and overcrowding of toes which were match-stick like in appearance with swollen distal phalanges.

There was mild valgus deformity of both knee joints with anteriorly projecting deformity at the junction of upper two-third and lower one-third of both thighs produced due to bilateral femur fracture.

Similarly, there were flexion contractures of both the wrist joints which was more pronounced in the left side with overcrowding of long and slender fingers. There were no other positive findings on general examination and the systemic examination was grossly normal.

His septic screening was negative with sterile blood culture and his CSF study along with Echocardiography and Ultrasonography of cranium and abdomen were all normal. Similarly, his Calcium level was low normal (2mmol/l) while his Phosphorus, Alkaline Phosphatase, Vitamin D3, PTH and CPK-MB were all within normal limit.

His X-rays showed bilateral fracture of shaft of femur with callus formation, decreased bone mineral density, absence of tibial epiphyses in both sides and the characteristic deformities. (Figure 3)

So, the child was diagnosed as a case of Bruck Syndrome with presumed sepsis on clinical and radiological basis and was managed with IV antibiotics for seven days after which the baby was discharged. No further investigations including the genetic studies could be done to confirm our diagnosis as they were not available in our set up. Meanwhile, during the baby's stay at NIMCU, orthopedic consultation was done and as per the advice hip spica was applied with physiotherapy planned after three weeks.

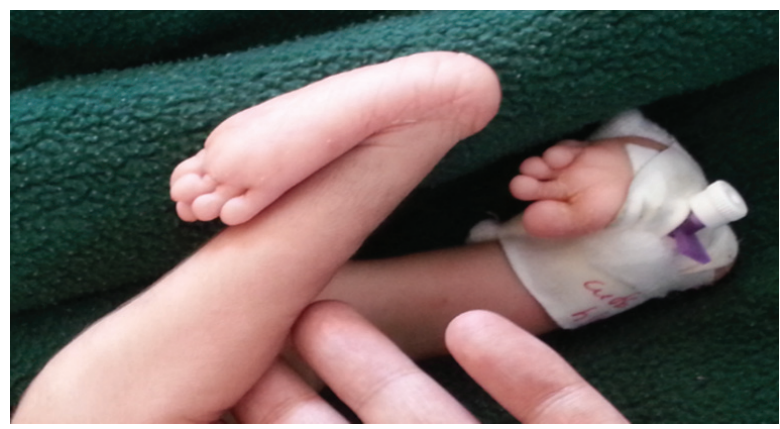

Fig 2: The typical flexion deformity of the ankle joints. 


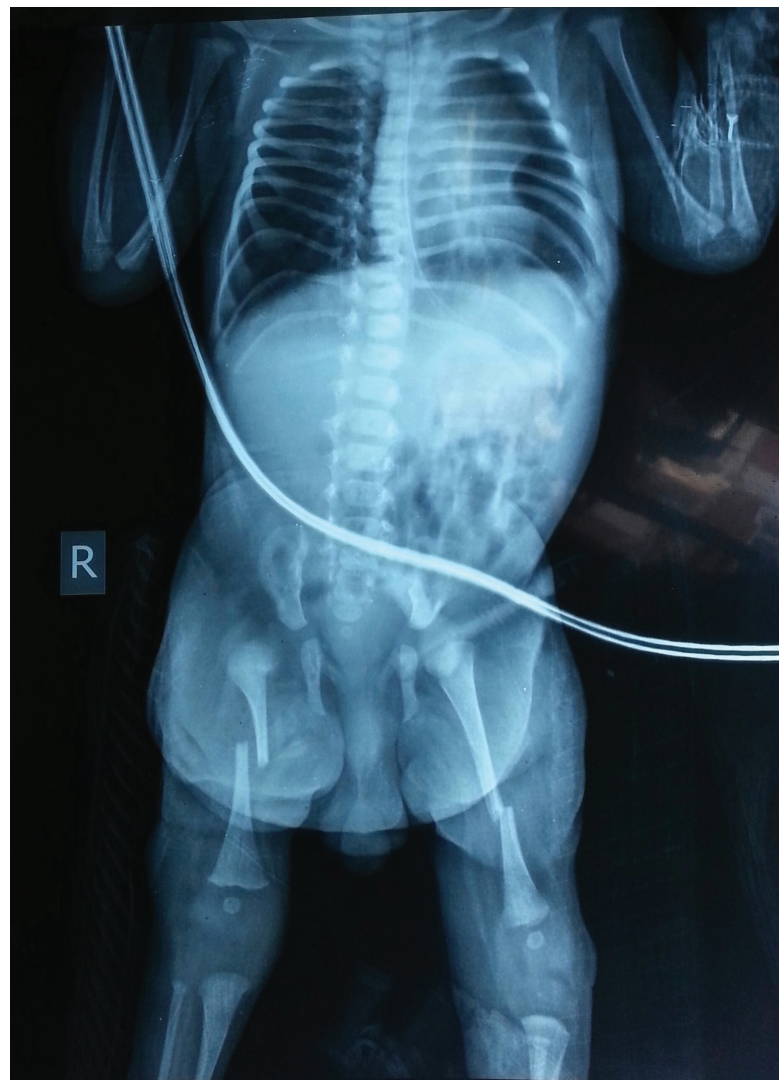

Fig 3: X-ray AP view showing bilateral femur fracture with callus formation, over tubulated bones with decreased bone density, absence of tibial epiphyses and long slender ribs.

\section{Discussion}

Bruck syndrome (BS) is an extremely rare congenital disorder presenting with the combination of symptoms of osteogenesis imperfect (OI) and arthrogryposis multiplex congenita ${ }^{1}$, which includes bone fragility manifesting as multiple and recurrent fractures and congenital joint contractures. It has been considered as an autosomal recessive form of osteogenesis imperfecta $(\mathrm{OI})^{1}$ while some cases have found to have sporadic mutation which must be the most probable mechanism in our case in the absence of family history.

BS has been classified into types 1 and 2 which are clinically indistinguishable ${ }^{6}$. BS type 2 has been linked to mutations in PLOD2 ${ }^{7,8}$. The etiology of type $1 \mathrm{BS}$ has not been determined, but it has been linked to chromosome 17 , possibly region $17 \mathrm{p} 12^{9}$. Recently, mutations in FKBP10, localized to chromosome 17q21, have been identified in some cases of $\mathrm{BS}^{6}$ that result into mutations in the gene for bone specific terminal lysyl hydroxylase I (TLH I). TLH I is involved in the cross-linking of type I collagen polypeptides prior to assembly of the triple helices by hydroxylation of lysine residue ${ }^{4}$.
However, with molecular diagnosis not available in most of the centres in our part of the world, a comprehensive history and a good clinical evaluation remains of the most important to delineate the basic abnormalities associated with this disorder. Clinically most of these patients present with congenital contractures with or without pterygia like in our case. Like in our case, they usually have white sclera and normal hearing and vision. Fractures occur at multiple and uncommon sites without any history of trauma and the contractures are the primary abnormality, and not the complication of fracture.

We did not perform the bone biopsy of our case due to unavailability of such facility, but Brenner et. al. ${ }^{10}$ performed the electron microscopy of the bone specimen of affected patient which showed the presence of osteoblasts with swollen mitochondria and dilated endoplasmic reticulum. They also noted a decrease in the diameter of the collagen fibrils along with low mineral content and increased pepsin extraction of collagen 1.

As discussed earlier, only about 28 cases with Bruck Syndrome have been reported. Among the latest reports, Breslau-Siderius et. al. ${ }^{11}$ reported a family with three children having Bruck syndrome. The 12 years old eldest sibling had severe contractures of the knee and ankle without reports of bone fractures, kyphosis, scoliosis, popliteal webbing, and local hypermobility in the wrists and fingers. Her seven years old sister had recurrent fractures of the femurs, local hypermobility in the wrist and finger joints, severe contractures at the hips, knees, and ankles, scoliosis, and kyphosis. Her two years old brother had contractures of the hips and right knee, and there was no webbing.

Similarly, Shaheen et al. ${ }^{5,6}$ described two brothers with Bruck syndrome. In the neonatal period, the index patient had severe flexion deformity of knees, ankles, and, to a lesser extent, elbows. At seven months age, he had a fracture of the femur as a result of trivial trauma, followed by multiple other long bone fractures in early childhood. He had normal appearance of the sclera and teeth. His radiologic features consisted of evidence of old healed fractures, severe flexion deformities of knees and ankles, and generalized osteopenia. His similarly affected 13 years old brother had frequent fractures and multiple joint contractures.

The disease is progressive and leads to severe limb deformities, short stature, progressive kyphoscoliosis and multiple fractures. Management involves multi-disciplinary team including orthopaedic care with fracture management, physiotherapy, rehabilitation and medical treatment. 
Like in cases of Ol, bisphosphonates have been shown to be safe and effective in treatment of osteoporosis in Bruck syndrome. Cyclic intravenous pamidronate is now the gold standard of treatment of Bruck syndrome with limited side effects like first dose fever and occasional nephrocalcinosis. Oral bisphophonates, such as alendronate and risedronate are currently undergoing clinical trials for establishing their safety and efficacy ${ }^{12}$.

\section{References}

1. Datta V, Sinha A, Saili A et al. Bruck syndrome. Indian J Pediatr 2005;72:441-2.

2. Bruck A. Ueber eine seltene Form von Erkrankung der Knochen und Gelenke. Dtsch Med Wschr 1897;23:15255. DOI:10.1055/s-0029-1204900

3. Alanay $\mathrm{Y}$, Avaygan $\mathrm{H}$, Camacho $\mathrm{N}$ et al. Mutations in the gene encoding the RER protein FKBP65 cause autosomal-recessive osteogenesis imperfecta. Am J Hum Genet 2010;86:551-59. DOI: 10.1016/j. ajhg.2010.02.022. Epub 2010 Apr 1.

4. Bank RA, Robins SP, Wijmenga $C$ et al. Defective collagen crosslinking in bone, but not in ligament or cartilage, in Bruck syndrome: indications for a bonespecific telopeptide-lysyl-hydroxylase on chromosome 17. Proc Natl Acad Sci USA 1999:96:1054-58.

5. Shaheen R, Al-Owain M, Sakati $\mathrm{N}$ et al. FKBP10 and Bruck syndrome: phenotypic heterogeneity or call for reclassifcation? Am J Hum Genet 2010;87:306-7; author reply 308. DOI: 10.1016/j.ajhg.2010.05.020

6. Shaheen R, Al-Owain M, Faqeih E, et al. Mutations in FKBP10 cause both Bruck syndrome and isolated osteogenesis imperfecta in humans. Am J Med Genet A 2011;155A:1448-52.

\section{Conclusion}

Bruck Syndrome is a very rare disease encountered by clinicians. So, whenever one comes across a child with brittle bones presenting with multiple fractures at uncommon sites and congenital joint contractures; Bruck Syndrome should also be suspected. Due to lack of molecular diagnosis, clinical and radiological diagnosis remains the cornerstone in our part of the world.

7. Ha-Vinh R, Alanay $\mathrm{Y}$, Bank RA et al. Phenotypic and molecular characterization of Bruck syndrome (osteogenesis imperfecta with contractures of the large joints) caused by a recessive mutation in PLOD2. $A m ~ J$ Med Genet A 2004;131:115-20.

8. Kelley $B P$, Malfait $F$, Bonafe $L$ et al. Mutations in FKBP10 cause recessive osteogenesis imperfecta and Bruck syndrome. J Bone Miner Res 2011;26:666-72. DOI: $10.1002 / j b m r .250$.

9. Yapicioglu H, Ozcan K, Arikan $\mathrm{O}$ et al. Bruck syndrome: osteogenesis imperfecta and arthrogryposis multiplex congenita. Ann Trop Paediatr 2009;29:159-62. DOI: 10.1179/146532809X440798.

10. Brenner RE, Vetter U, Stoss H, Muller PK, Teller WM. Defective collagen fibril formation and mineralization in osteogenesis imperfecta with congenital joint ontractures. Eur J Pediatr 1993;152:505-8.

11. Breslau-Siderius, E. J., Engelbert, R. H. H., Pals, G., van der Sluijs, J. A. Bruck syndrome: a rare combination of bone fragility and multiple congenital joint contractures. $J$ Pediatr Orthop 1998;7:35-38

12. Sillence DO. Disorders of bone density,volume and mineralisation. In Emery and Rimoins, eds.Principles Prac Med Gen. Vol.34th edn. Philadelphia; Churchill Livingstone, 2002; 4116-26. 